\title{
APLIKASI SENSOR PVDF UNTUK PENGUKURAN PERGESERAN SUDUT
}

\author{
Ambran Hartono ${ }^{1 *}$, Nurul Fadillah ${ }^{1}$, Edi Sanjaya ${ }^{1}$ \\ ${ }^{1}$ Program Studi Fisika, FST Universitas Islam Negeri Syarif Hidayatullah \\ Jl. Juanda 95 Ciputat Tangerang Selatan, 17115, Indonesia \\ *ambran.hartono@uinjktac.id,nurulf@gmail.com, edisanjaya@uinjkt.ac.id,
}

\begin{abstract}
In this paper we will present the results of the study at the application of Polyvinylidene Fluoride (PVDF) sensors to determine the value of angular shift. In the study carried out the loading on the PVDF sensor so that the PVDF film on the sensor changes in the form of angular shift. For every angle shift that occurs then the sensor will detect in the form of output current on the display. The sensor loading is done for the angle change ranges from $10^{\circ}$ to $80^{\circ}$. From the research results show that the sensor output shows a mathematical relationship between the magnitude of the angular shift with the resulting current. The mathematical relationship is expressed in terms of exponential equations. This clearly indicates that this PVDF sensor can work well in detecting large angular changes.
\end{abstract}

Keywords: Angle displacement, Current, Piezoelectric, PVDF Sensor

\section{PENDAHULUAN}

Pemanfaatan film polimer sebagai sensor akhir-akhir ini semakin pesat, khususnya polimer Polyvinyldene Fluoride (PVDF). PVDF merupakan suatu bahan plastik khusus dalam keluarga polimer fluor yang umumnya digunakan dalam aplikasi yang memerlukan kemurnian yang tinggi, kuat dan tahan terhadap pelarut.

Polimer

PVDF diketahui mempunyai tiga bentuk struktur molekul padat yaitu struktur $\alpha$, struktur $\beta$ dan struktur $\gamma$. Struktur $\beta$ mempunyai rantai molekul dengan konformasi planar zigzag semuanya trans (TTTT). Setiap ikatan atom karbon (C) dengan atom fluor (F) memiliki arah resultan momen dipol tertentu dan atom karbon juga berikatan dengan hidrogen $(\mathrm{H})$ memiliki resultan arah momen dipol yang searah dengan resultan antara ikatan atom karbon dengan fluor.

Struktur $\alpha$ mempunyai dua rantai molekul dengan tipe TGTG. Masingmasing dihubungkan dengan pusat simetri yang mempunyai hubungan simetri invers satu sama lain, sehingga mengakibatkan momen dipol lisrik total dari seluruh kristal saling meniadakan. Rantai molekuler bentuk ini mempunyai polarisasi dengan dipol-dipol acak, sehingga secara keseluruhan kristalnya adalah non polar.

Struktur $\gamma$ merupakan fasa campuran antara struktur $\beta$ dan struktur $\alpha$. Struktur ini mempunyai nilai momen dipol tertentu namun nilainya masih 
E-ISSN : 2549-7464, P-ISSN : 1411-3724

relatif kecil. Diantara ketiga struktur tersebut, yang banyak dikembangkan adalah PVDF dengan fase struktur $\beta$ karena memberikan efek piezoelektrik yang paling besar dibandingkan dengan kedua fase struktur lainnya (Ambran dkk, 2013).

\begin{tabular}{lcr}
\multicolumn{3}{c}{ Studi tentang aplikasi sensor PVDF } \\
telah dilakukan & terutama & yang \\
berhubungan & dengan & sifat \\
piezoelektriknya. & Vinogadrov & dan
\end{tabular}
Holloway (1999) telah meneliti pengaruh sudut fasa dari PVDF. Demikian juga halnya dengan Prananto yang meneliti perubahan beda potensial terhadap pengaruh sudut gangguan luar yang diberikan secara langsung terhadap film (Prananto D dan Mawarani L, 2010). Akan tetapi hasil dari penelitian ini belumlah mengungkap dengan lengkap bagaimana hubungan perubahan sudut dengan respon keluaran sensor PVDF secara matematis.

Kedepannya dengan adanya kajiankajian seperti ini aplikasi yang lebih jauh lagi bisa diterapkan dari sensor ini seperti halnya dalam mendeteksi reruntuhan, gejala gempa bumi dan tanah longsor.

Salah keunikan dari material PVDF ini adalah dengan sifat piezoelektrisitasnya. Suatu material dikatakan bersifat piezoelektrik jika dikenakan stress mekanik menghasilkan polarisasi listrik atau sebaliknya. Sedangkan jika perubahan polarisasi momen dipol listrik diakibatkan oleh perubahan temperatur maka material tersebut dikatakan bersifat piroelektrik. PVDF merupakan bahan feroelektrik, yaitu yang mengandung kristal kutub yang arah polarisasinya dapat dibalik dengan aksi medan listrik.

Sebagaimana telah diketahui bahwa piezoelektrisitas merupakan kemampuan suatu material untuk memberikan respon elektrik akibat adanya gangguan mekanik. Saat diberikan tekanan mekanik, muatan listrik akan muncul diantara dua sisi berlawanan pada bahan piezoelektrik. Efek ini juga dapat terjadi sebaliknya, yaitu terjadinya deformasi bentuk material berupa stress mekanis yang berasal dari medan listrik yang diberikan, kejadian ini disebut sebagai efek piezo balik (Ueberschlag P, 2001). Material yang dapat mengalami efek-efek tersebut salah satunya adalah kelompok material polimer. Ilustrasi dari adanya gangguan mekanik yang diberikan pada sensor PVDF dan rensponya seperti di perlihatkan pada Gambar 1.

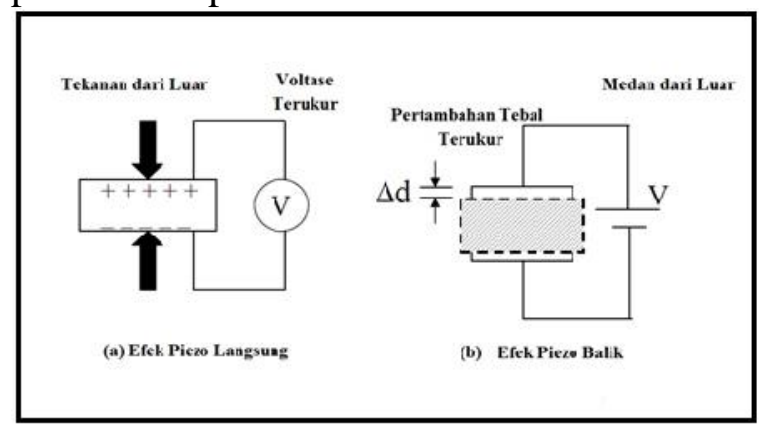

Gambar 1. Ilustrasi Efek Piezo (a) Langsung (b) Balik (Ueberschlag P, 2001).

Bila pusat muatan positif tidak berimpit dengan pusat muatan negatif sehingga akan terbentuk dipol listrik antara kedua pusat muatan tersebut. Kristal yang tidak memiliki pusat simetri dibagi menjadi dua bagian yaitu kristal polar dan krisal nonpolar. Kristal polar mengandung vektor polar dalam arah singular sehingga terjadi polarisasi spontan. Sedangkan kristal non-polar mengandung vektor polar tidak dalam arah singular tetapi secara acak sehingga secara keseluruhan jumlah vektor polarnya berharga nol. Bahan polimer dan keramik termasuk inaktif karena terdiri 
dari banyak domain yang berorientasi secara acak sehingga tidak dapat menunjukkan sifat piezoelektriknya. Untuk mengaktifkannya harus diusahakan agar polarisasi total dari keduanya tidak berharga nol, yaitu dengan cara menyearahkan orientasi dipol listriknya melalui polling sehingga hampir sejajar

Kristal yang tidak memiliki pusat simetri ini menghasilkan muatan elektrik ketika terjadi perubahan mekanik yang disebabkan oleh induksi momen dipol. Ini dikarenakan perpindahan asimetris dari pusat gravitasi muatan positif dan negatif. Secara bergantian, molekul-molekul itu memberikan strain untuk mengimbangi kehadiran medan luar yang disebabkan oleh perpindahan muatan dari tarikan dan tolakan elektrostatik.

Penjelasan umum mengenai piezoelekitisitas telah dikembangkan oleh Hayakawa and Wada (1976), yang diekspresikan oleh persamaan beda potensial untuk rangkaian terbuka

$$
\begin{aligned}
& V_{o p}=-\frac{4 \pi}{\tau}\left(1-\frac{k}{t}\right) \int_{-\frac{1}{2}}^{\frac{1}{2}} d x\left[u(x)-\frac{\delta l}{l}\right] \times \\
& \int_{-\frac{1}{2}}^{x} p(x) d x+\frac{4 \pi \varepsilon_{i n t} t \delta}{t}
\end{aligned}
$$

Hubungan pertama sesuai dengan sifat piezoelektrisitas yang mana hasil dari kombinasi dari distribusi muatan $\rho(\mathrm{x})$ dan strain yang tidak merata.

$$
\left[u(x)-\frac{\delta l}{l}\right]
$$

dan hubungan kedua sesuai dengan piezoelektrisitas intrinsik yang disebabkan oleh strain dalam pada sebuah bagian sel dari kristal polar atau secara umum dikenal sebagai kristal asimetrik. Formula tersebut mengindikasikan bahwa piezoelektrisitas dapat terjadi tak hanya pada kristal asimetrik tapi juga pada material amorf yang terpolarisasi. Persamaan tersebut menunjukan bahwa peristiwa piezoelektrik sangat dekat hubungannya dengan elektrostriksi dan fenomena viskoelastik.

Konstanta piezolektrik merupakan parameter yang digunakan untuk menggambarkan kopel elektromekanis antara perpindahan elektrik (D) atau medan (E) pada satu sisi, dan stress (X) atau strain (L) pada sisi lainnya, pada temperatur konstan (T). Konstanta d yang merupakan konstanta piezoelektrik strain adalah salah satu konstanta yang paling sering dipakai. Konstanta $d$ dapat diekspresikan sebagai:

$$
d=\left(\frac{\partial D}{\partial X}\right)_{E=O: T}=\left(\frac{\partial P}{\partial X}\right)_{E=O: T}
$$

Adanya pembebanan terhadap film PVDF pada sensor mengakibatkan terjadi transformasi perubahan dalam struktur PVDF pada sensor. Respon yang diberikan oleh sensor bergantung seberapa besar pembebanan yang dikenalkan pada sensor. Bentuk keluaran yang dihasilkan dari sensor disajikan dalam bentuk arus pada display. Besarnya arus yang ditampilkan oleh sensor sebanding dengan perubahan sudut dari film PVDF akibat pembebanan.

\section{METODE PENELITIAN}

Penelitian yang dilaksanakan adalah eksperimental. Penelitian dilakukan dengan proses diperlihatkan secara skematik dalam Gambar 2. Beberapa bahan dan peralatan yang dibutuhkan dalam penelitian ini antara lain Alat ukur I-V meter merk ELKAHFI 100 (berfungsi untuk membaca keluaran arus-tegangan 


\section{Eksakta Vol. 18 No. 2 Oktober $\mid 2017$}

E-ISSN : 2549-7464, P-ISSN : 1411-3724

yang dihasilkan), Kabel USB Probe CH9 (berguna untuk menghubungkan alat ukur ke PC), Busur derajat (berfungsi untuk melihat besar perubahan sudut), Film tipis PVDF dan batang penyanggah (untuk dudukan film PVDF).

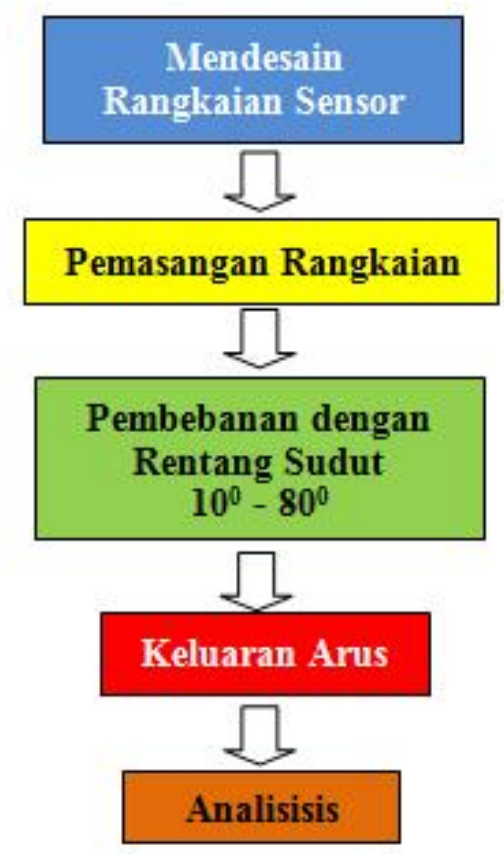

Gambar 2. Diagram alir penelitian

Bahan baku film PVDF adalah
dengan tipe DT1-052K buatan
Measurement Specialities ${ }^{\mathrm{TM}}$, (Gambar 3)
dengan spesifikasi yaitu: tebal film PVDF
$52 \mu \mathrm{m}$, panjang layer PVDF 23,5 mm dan
lebar $1,2 \mathrm{~mm}$, dengan nilai permitivitas
bahan sekitar $1,06 \times 10^{-12} \mathrm{Fm}^{-1}$ sampai
$1,13 \times 10^{-12} \mathrm{Fm}^{-1}$. Film PVDF ini sudah
dilengkapi elektroda di masing-masing
sisi filmnya sehingga memudahkan dalam
pengukuran yang mengharuskan
dilakukannya penghubungan dari maupun
ke kabel input dan output I-V meter.
Adapun film yang digunakan sebanyak 5
(lima) buah sampel yaitu S1, S2, S3, S4,
dan S5.

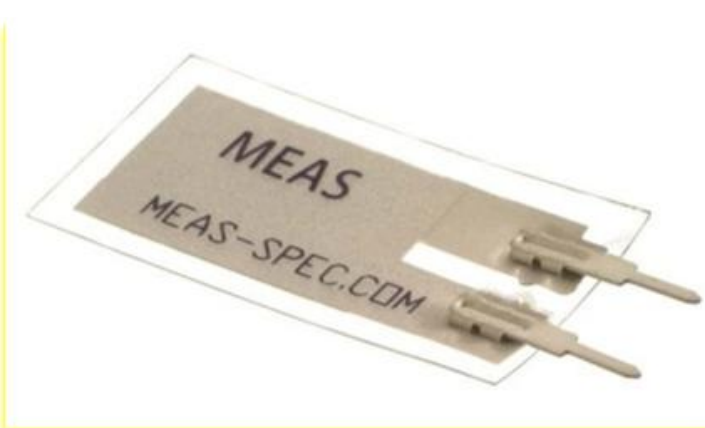

Gambar 3 Sampel film PVDF

Pelaksanaan penelitian ini dilakukan dengan melakukan set up perangkat/instrumen percobaan dan memasang software dan driver Elkahfi pada komputer untuk memudahkan dalam penyimpanan hasil keluaran arus yang terukur, tahap selanjutnya adalah menyiapkan I-V meter elkahfi 100 untuk dipasangkan kabel input dan output-nya ke masing-masing kaki elektroda dari sampel film PVDF untuk diukur arus keluarannya. Tegangan masukan yang diberikan dari rentang 0 sampai 9 Volt, dengan kenaikan sebesar 0,05 Volt. Pengaturan ini bisa diubah melalui komputer.

Berikutnya, dilakukan pemasangan (set up) rangkaian sensor PVDF dan pengujian secara keseluruhan. Rangkaian sensor dan eksepeimen terpasang seperti ditampilkan pada Gambar 4.

Selanjutnya dilakukan pengukuran dan pengambilan data. Pengambilan data dalam eksperimen ini adalah pengabilan data arus keluaran sensor akibat pembebanan pada sensor PVDF. Pembebanan dilakukan untuk rentang perubahan sudut dari $10^{\circ}$ sampai dengan $80^{\circ}$. Pengambilan data dilakukan berulang-ulang sehingga didapatkan data keluaran arus yang stabil. 
Eksakta Vol. 18 No. 2 Oktober $\mid 2017$

E-ISSN : 2549-7464, P-ISSN : 1411-3724

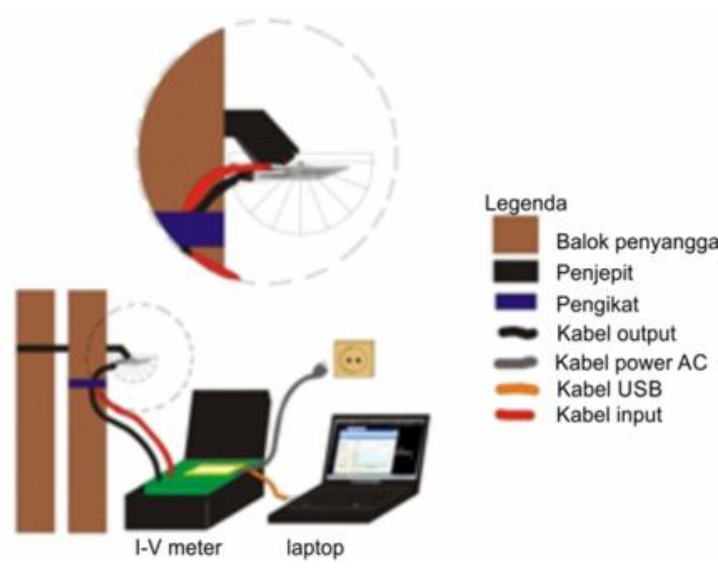

Gambar 3. Rangakaian pegukuran (Nurul, 2016)

\section{HASIL DAN PEMBAHASAN}

Dari hasil eksperimen yang telah dilakukan diperoleh data keluaran arus terhadap pembebanan (perubahan sudut) sebagaimana ditampilkan dalam Tabel 2.

Dari data hasil eksperimen yang telah dilakukan terlihat bahwa terdapat fakta menarik yaitu tampilan data arus keluaran terhadap adanya perubahan sudut. Dari data jelas terlihat kecenderungan trend kenaikan arus keluaran dengan perubahan sudut. Fakta ini juga bisa dengan jelas dapat kita lihat dengan melihat data-data hasil keluaran arus tersebut yang disajikan dalam bentuk plot grafik seperti ditampilkan pada Gambar 5.

Tabel 2 Data arus keluaran dari 5 buah sampel PVDF terhadap perubahan sudut.

\begin{tabular}{|c|c|c|c|c|c|}
\hline Sudut & \multicolumn{5}{|c|}{ Arus (x 10-8 $\mathbf{A})$} \\
\cline { 2 - 6 }$($ derajat $)$ & $\mathbf{s 1}$ & $\mathbf{s 2}$ & $\mathbf{s 3}$ & $\mathbf{s 4}$ & $\mathbf{s 5}$ \\
\hline 10 & 1,78 & 1,92 & 2,01 & 1,82 & 1,69 \\
\hline 20 & 2,31 & 2,35 & 2,3 & 2,26 & 2,55 \\
\hline 30 & 3,12 & 3,1 & 3,15 & 3,09 & 3,11 \\
\hline
\end{tabular}

\begin{tabular}{|c|c|c|c|c|c|}
\hline 40 & 4,21 & 4,32 & 4,22 & 4,2 & 4,25 \\
\hline 50 & 5,15 & 5,05 & 5,2 & 5,13 & 5,17 \\
\hline 60 & 6,36 & 6,55 & 6,37 & 6,35 & 6,45 \\
\hline 70 & 8,25 & 8,33 & 8,27 & 8,3 & 8,22 \\
\hline 80 & 11,01 & 11 & 11,25 & 11,03 & 11 \\
\hline
\end{tabular}

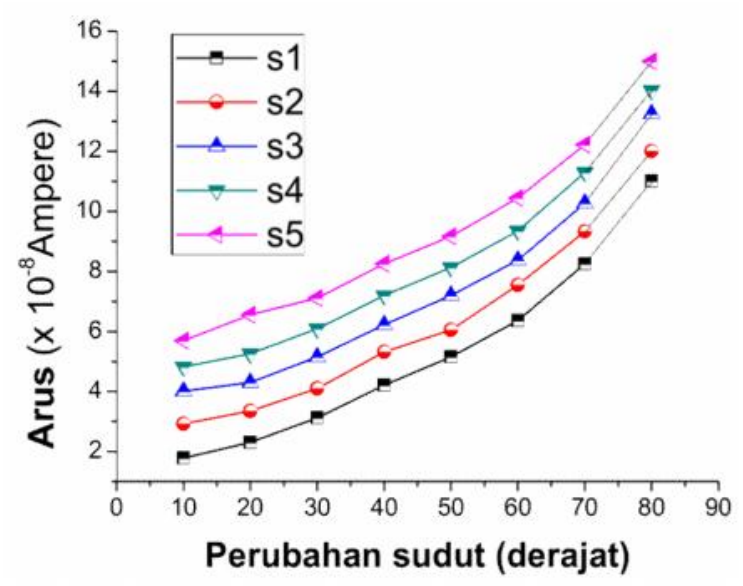

Gambar 5. Grafik kurva arus terhadap perubahan sudut untuk 5 buah sampel secara terpisah

Berdasarkan Gambar 5 jelas terlihat bahwa terdapat hubungan matematis antara data keluaran arus dari sensor terhadap perubahan sudut yang terjadi. Selain itu juga kita bisa melihat bahwa eksperimen yang dilakukan berhasil dengan baik yang ditandai dengan hasil keluaran arus dari masing-masing sampel terhadap perubahan sudut.

Dalam bentuk lain kita juga bisa sajikan tampilan grafik untuk keluaran arus terhadap perubahan sudut dari kelima sampel yang diujikan. Plot grafik ini ditunjukkan pada Gambar 6. Dalam Gambar 6 jelas terlihat bahwa plot arus 
dari masing-masing sampel tampak berimpit yang menandakan bahwa hasil pengujian terhadap ke-lima sampel tersebut berhasil dengan baik.

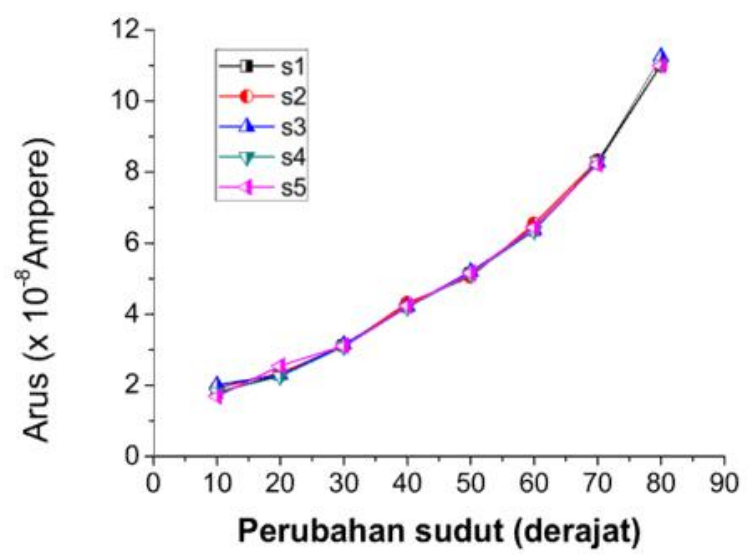

Gambar 6. Plot grafik kurva arus terhadap perubahan sudut untuk 5 buah sampel secara bersamaan.

Dari data-data di atas memperlihatkan bahwa terdapat hubungan matematis antara arus keluaran yang dihasilkan terhadap perubahan sudut yang terjadi. Hubungan antara keduanya berbentuk suatu persamaan eksponensial yaitu : $I(\theta)=1,417 \mathrm{e}^{0,025 \theta}$. Secara umum formulasinya dapat kita tuliskan sebagai berikut:

$$
\mathrm{I}(\theta)=\mathrm{ae}^{\mathrm{b} \theta}
$$

Fakta ini sangat menarik untuk dilakukan pengembangan misalnya untuk pengukuran kecepatan sudut putaran, sehingga bisa dihasilkan terobosanterobosan yang lebih banyak lagi.

\section{KESIMPULAN}

Telah berhasil dibuat sensor PVDF yang dapat diaplikasikan untuk mengukur nilai perubahan sudut. Dari hasil pengujian eksperimen di temukan fakta bahwa adanya hubungan matematis dalam bentuk persamaan eksponensial antara arus keluaran dengan perubahan sudut yang diberikan.

\section{UCAPAN TERIMAKASIH}

Ucapan terima kasih sebesar-besarnya penulis sampaikan kepada "Lembaga Penelitian dan Pengabdian kepada Masyarakat (LP2M) UIN SYARIF HIDAYATULLAH JAKARTA" atas dukungan teknis dan moril yang telah diberikan.

\section{DAFTAR PUSTAKA}

Ambran, H., Satira, S., Mitra, D., Ramli, R., Herman, B., Edi, S., (2013), Effect of Mechanical Treatment Temperature on Electrical Properties and Crystallite Size of PVDF Film, Advances in Material Physics and Chemistry, 3, 71-76.

Bachmann. M. A., \& Lando, J.B (1981),

A Recomendation of the crystal structure of phase II of Polyvinylidene Fluoride,

Macromolecules, 14(1), 40-46

Hayakawa, R., \& Wada. Y, (1973),

Piezoelectricity and related propeerties of polymer films. In Fortschritje der hochpolymerenForschung (pp.1-55) Springer Berlin Heidelberg

Nurul F., (2016), Analisis Pengaruh

Sudut Gangguan Terhadap

Perubahan Polarisasi Film

Polyvinylidene Fluoride, Skripsi

Fisika FST, UIN Jakarta.

Prananto. D dan Mawarni L,(2010),

Karakterisasi Smart Material

Polyvinylide Fluoride (PVDF) sebagai Transducer Piezoelektirk, 
Surabaya Institut Teknologi

Sepuluh Nopember, tersedia pada laman web:

https://www.researchgate.net/profil

e/Lizda_Mawarani/publication, diunduh tanggal 6 November 2017.

Ucherschlag. P, (2001), PVDF

Piezolelectric Polymer Sensor

Review, 21(2), 118-126.
Vinogradov, A., \& Holloway, F., (1999), Electro-mechanical properties of the piezoelectric polymer PVDF, Ferroeletrics, 226(1), 169-181

Wada, Y., \& Hayakawa, R., (1976), Piezoelectricity and pyroelectricity of polymers, Japanese Journal of Applied Physics, 15(11), 2041 